\title{
AVAliaÇ̃̃o DE CUlTiVARES DE FEIJÃO (Phaseolus vulgaris) PARA O PLANTIO EM SISTEMA ORGÂNICO NO DISTRITO FEDERAL
}

\author{
Field bean (Phaseolus vulgaris) cultivars evaluation for crop in organic system \\ in the state of Distrito Federal
}

\author{
Wellington Pereira de Carvalho', Alberto Luiz Wanderley²
}

\begin{abstract}
RESUMO
O presente estudo se propôs a indicar cultivares de feijão (Phaseolus vulgaris) que tenham melhor desempenho no sistema orgânico, além de mostrar que o rendimento ótimo sustentável conseguido pela agricultura orgânica, pode estar muito próximo do rendimento potencial conseguido pela agricultura convencional. No ano de 2003, foram instalados dois ensaios, um irrigado e outro no período das águas, em uma área de pastagem de baixa fertilidade, situação semelhante à encontrada pelos produtores que se iniciam na produção orgânica sem passar pelo período de conversão, utilizando áreas que se encontram em descanso há alguns anos ou pastagens que não receberam aplicações de agrotóxicos ou adubos de alta solubilidade. No ano seguinte, os mesmos ensaios foram instalados em outra área com fertilidade corrigida e equilibrada, situação em que se encontram produtores já enquadrados na atividade orgânica. Utilizou-se delineamento experimental de blocos ao acaso com quatro repetições. As cultivares avaliadas foram: Diamante Negro, Talismã, Xamego, Marfim, Jalo Precoce, Pérola, Timbó, Radiante, Aporé, Valente e Vereda. Dentre as cultivares empregadas destacaram-se as dos grupos comerciais preto e carioca, os tipos de maior demanda na região do Distrito Federal.
\end{abstract}

Termos para indexação: Produtividade, avaliação de cultivares, agroecossistema, agricultura orgânica.

\begin{abstract}
This study objectified indicate field beans (Phaseolus vulgaris) cultivars that have better performance in organic system, besides to show that the optimum sustainable yield, that can be managed by organic agriculture can be close to potential yield managed by the conventional agriculture. Two experiments were established during the year 2003, one under irrigation system in the dry season and the other in the wet season, in an area with brachiaria pasture with low fertility, the same situation of growers who choose to join the organic system without the necessity of passing through the conversion period, using areas that have been in rest for few years or pastures that doesn't have pesticides or soluble fertilizers aplications. In the subsequent year, the same experiments were established in other area with corrected and equilibrated fertility, the same situation of the growers fitted in the organic activity. A randomized complete block design with four replications was used. It was evaluated the cultivars Diamante Negro, Talismã, Xamego, Marfim, Jalo Precoce, Pérola, Timbó, Radiante, Aporé, Valente and Vereda The best performing cultivars were from "black" and "carioca" commercial groups, which are the most demanded types in the region of the State of Distrito Federal.
\end{abstract}

Index terms: Productivity, cultivars evaluation, agroecosystem, organic agriculture.

(Recebido em 4 de novembro de 2005 e aprovado em 22 de dezembro de 2006)

\section{INTRODUÇÃO}

O processo de mudança do manejo convencional para o orgânico tem sido chamado de "conversão". Normalmente, esse processo requer um período de dois anos para que ocorra a resituação do produtor e do ambiente e, quando se dá em uma área onde havia intensa produção convencional, geralmente, há queda na produtividade até que se consiga equilibrar o ambiente com o objetivo de alcançar a sustentabilidade (KHATOUNIAN, 1999). Outra forma de se conseguir a qualificação para o uso do selo orgânico, sem necessitar do período de quarentena, é o plantio em áreas que estiveram em repouso ou utilizadas como pastagens onde não se tenha feito o uso de agrotóxicos e fertilizantes de alta solubilidade durante dois anos ou mais. Muitos produtores optam por iniciar a atividade nesse tipo de situação. Geralmente, essas áreas possuem baixa fertilidade do solo e necessitam ser trabalhadas até atingirem o equilíbrio que proporcione uma produtividade satisfatória.

A agricultura orgânica, em áreas já certificadas, é formada predominantemente por pequenas e médias propriedades e, em grande parte delas, caracteriza-se o cultivo de hortaliças com pouca diversidade de culturas em uma mesma unidade produtiva. $\mathrm{O}$ cultivo continuado das mesmas espécies vegetais normalmente aumenta a incidência de doenças e pragas quando os agentes transmissores permanecem nos restos culturais. Uma seqüência de culturas pode cortar esse ciclo, evitando, assim, sua expansão. A introdução de grãos no sistema torna-se uma necessidade, sobretudo, por ser uma

${ }^{1}$ Engenheiro Agrônomo, Mestre, Pesquisador - Embrapa Cerrados/CPAC - Cx. P. 08223 - 73310-970 - Planaltina, DF - well@cpac.embrapa.br Engenheiro Agrônomo - Itec Biotecnologia Agrícola - SHCES 411 - Bloco B - Loja 10 - 70650400 - Brasília, DF - alberto@loreno.net 
alternativa para rotação de culturas que quebra o ciclo de infestação de doenças e do ataque de pragas.

Uma estratégia para se conseguir boa produtividade, mantendo a estabilidade do agroecossistema, é o uso de variedades adaptadas à região. Segundo Wanderley (2001), as seguintes medidas contribuem para elevar a sustentabilidade do agroecossistema: associar barreiras de quebra-vento; rotação de culturas com diferentes espécies; cultivo em faixas alternadas, com diferentes épocas de preparo e plantio; manutenção de faixas de abrigo, ou seja, áreas com vegetação nativa, mantidas na área de cultivo e o uso de cultivares adaptadas a cada região.

No Brasil, existem poucos trabalhos científicos envolvendo sistema orgânico de produção. Assim, a oferta tecnológica adequada a esse sistema ainda é muito incipiente (CARVALHO, 1999). Atualmente, a maioria das informações de circulação nacional é de caráter especulativo e sem base científica, e grande parte é proveniente de iniciativas práticas dos agricultores ou embasadas em experiências internacionais. Importantes contribuições têm ocorrido com trabalhos específicos por áreas de conhecimento, realizados em cultivos orgânicos isolados (SORAGY et al., 1998) ou estudando temas de interesse da agricultura orgânica, porém em cultivos convencionais, enfocando uso de biofertilizantes, adubação verde e adubações orgânicas, entre outros.

Uma grande lacuna a ser preenchida com respeito à pesquisa em agricultura orgânica relaciona-se à adaptação do cultivo de graníferas a esse sistema de produção e a maioria dos trabalhos existentes refere-se à cultura da soja, na Região Sul do País.

Um dos objetivos deste estudo foi indicar cultivares de feijão que tenham melhor desempenho, tanto no plantio irrigado como no de sequeiro, servindo de base para produtores que pretendem iniciar-se no sistema orgânico sem passar pelo período de conversão ou para produtores que já se encontram inseridos no sistema e contam com área já certificada, com uma cultura que tem valor agregado, preço diferenciado, procura maior que a oferta e que é uma excelente opção para rotação de culturas, proporcionando rápido retorno do capital investido.

Embora haja consenso entre especialistas em agroecologia que as técnicas orgânicas, por trabalharem na perspectiva de sustentabilidade, dificilmente alcançariam altas produtividades, próximas ao rendimento potencial das culturas, por não serem compatíveis com a preservação dos meios de produção nem do ambiente (KHATOUNIAN, 1999), outro objetivo deste trabalho foi mostrar que o rendimento ótimo sustentável, conseguido pela agricultura orgânica, preservando os meios de produção e o ambiente, pode estar próximo desse rendimento potencial conseguido pela agricultura convencional.

\section{MATERIAL E MÉTODOS}

A área experimental foi instalada na fazenda Moça Terra, de propriedade da empresa Itec-Biotecnologia Agrícola Ltda, localizada nas coordenadas S $15^{\circ} 41^{\prime} 23,7^{\prime \prime}$ e W 47³4'18,5", a 1110 m de altitude, no Núcleo Rural Santos Dumont, situado no Plano de Assentamento Dirigido do Distrito Federal (PAD-DF), em um Latossolo VermelhoAmarelo de textura argilosa. Os ensaios foram conduzidos na forma de Teste de Avaliação Local (TAL), sendo que as cultivares Diamante Negro, Talismã, Xamego, Marfim, Jalo Precoce, Pérola, Timbó, Radiante, Aporé, Valente e Vereda constituíram os tratamentos. Foram avaliados vários tipos de feijão, atendendo à diversificação do gosto do consumidor, pesquisado nas feiras de produtos orgânicos de Brasília. Foram conduzidos quatro ensaios, nos anos de 2003 e 2004, dois irrigados na época da seca e dois de sequeiro na época das águas, cultivados em sistema orgânico de produção e seguindo os princípios e normas técnicas da CMO (Certificadora Mokiti Okada). O delineamento experimental foi blocos ao acaso, com quatro repetições. As parcelas foram constituídas de quatro linhas de $4 \mathrm{~m}$ de comprimento, com espaçamento de $0,5 \mathrm{~m}$ entre linhas, sendo as duas linhas externas utilizadas como bordadura. As características avaliadas foram: rendimento de grãos, estande final e incidência de pragas e doenças. O rendimento de grãos, com umidade corrigida para $13 \%$ foi estimada em $\mathrm{kg} / \mathrm{ha}$, em função da produção de grãos na área útil de cada parcela experimental.O estande final foi obtido por meio da contagem de todas as plantas nas duas linhas centrais das parcelas. A avaliação das doenças antracnose (Colletotrichum lindemuthianum), murcha-defusário (Fusarium oxysporum) e mancha-angular (Phaeoisariopsis griseola) foi feita visualmente utilizandose escala descrita por Rava et al. (1993) para antracnose, escala proposta por Rava et al. (1996) para murcha-defusário e para mancha-angular, diagrama de notas preconizado por Sartorato \& Rava (2003). Não foi constatada incidência de antracnose e o número de plantas infectadas por murcha-de-fusário foi pequeno, não permitindo sua análise estatística. A doença que ocorreu com maior severidade foi mancha-angular. A incidência e a severidade do ataque de pragas foram determinadas durante todo o ciclo da cultura, usando-se a metodologia preconizada por Quintela (2001). As análises estatísticas

Ciênc. agrotec., Lavras, v. 31, n. 3, p. 605-611, maio/jun., 2007 
foram feitas no programa computacional SAS, e como houve homogeneidade de variância, procedeu-se a análise individual e conjunta dos dados de rendimento de grãos, comparando-se as médias pelo teste de Tukey a 5\% de probabilidade. A semeadura foi manual, com quinze sementes por metro, inoculadas com as estirpes PRF $81 \mathrm{e}$ CIAT 899 de Rhizobium propici.

O primeiro ensaio foi instalado em área com solo de baixa fertilidade, ocupada há mais de dois anos com pastagem de braquiária, no período de inverno, no mês de julho de 2003, sendo usado sistema de irrigação por aspersão convencional fixo. O preparo do solo constou inicialmente de uma aração com grade aradora. Em seguida, foi aplicado produto composto de cultura de microrganismos fermentadores capazes de acelerar processos de decomposição e reciclagem de matéria orgânica. Após a decomposição da braquiária, foram realizadas duas gradagens com niveladora, sendo a última, um dia antes do plantio. Logo depois, foram abertos manualmente os sulcos de plantio, onde foram aplicados, como adubação de base, $1000 \mathrm{~kg} / \mathrm{ha}$ de composto orgânico farelado (0,7 kg/ha N; 34,2 kg/ha $\mathrm{P}_{2} \mathrm{O}_{5}$ e $\left.16,8 \mathrm{~kg} / \mathrm{ha} \mathrm{K}_{2} \mathrm{O}\right)$, Fosfato de Arade na dosagem de $1000 \mathrm{~kg} / \mathrm{ha}$ e Sulfato de Potássio na dosagem de $60 \mathrm{~kg} / \mathrm{ha}$ quantidades baseadas nos dados da análise de solo. Na adubação de cobertura, utililizou-se composto orgânico farelado na quantidade de $800 \mathrm{~kg} / \mathrm{ha}\left(0,6 \mathrm{~kg} / \mathrm{ha} \mathrm{N} ; 27,4 \mathrm{~kg} / \mathrm{ha} \mathrm{P}_{2} \mathrm{O}_{5}\right.$ e $13,4 \mathrm{~kg} / \mathrm{ha} \mathrm{K} \mathrm{K}_{2}$ ). $\mathrm{O}$ controle de plantas infestantes foi feito com uma capina manual aos trinta dias após a germinação.

O segundo ensaio foi instalado no período das águas, no mês de dezembro de 2003, na mesma área do primeiro ensaio, com preparo do solo, adubação e condução semelhantes ao cultivo anterior. Aos 45 dias após a emergência, foi realizada uma pulverização preventiva com calda bordalesa a $1 \%$ para controle de doenças fúngicas, comuns nessa época, principalmente, mancha-angular.

O terceiro ensaio foi instalado numa área com fertilidade equilibrada, onde já se praticava o cultivo orgânico há alguns anos, no período de inverno, no mês de junho de 2004, sendo usado sistema de irrigação por aspersão convencional fixo. O preparo do solo constou inicialmente de uma aração com arado de discos e duas gradagens com niveladora, sendo a última um dia antes do plantio. Em seguida, foram abertos manualmente os sulcos de plantio onde foram aplicados, como adubação de base, $800 \mathrm{~kg} / \mathrm{ha}$ de composto orgânico farelado $(0,6 \mathrm{~kg} / \mathrm{ha} \mathrm{N}$; $27,4 \mathrm{~kg} / \mathrm{ha} \mathrm{P}_{2} \mathrm{O}_{5}$ e $13,4 \mathrm{~kg} / \mathrm{ha} \mathrm{K}_{2} \mathrm{O}$ ), Fosfato de Arade na dosagem de $800 \mathrm{~kg} / \mathrm{ha}$ e Sulfato de Potássio na dosagem de $60 \mathrm{~kg} / \mathrm{ha}$, quantidades baseadas nos dados da análise de solo. Na adubação de cobertura usou-se o mesmo composto orgânico farelado na quantidade de $800 \mathrm{~kg} / \mathrm{ha}$. $\mathrm{O}$ controle de plantas infestantes foi feito com uma capina manual aos trinta dias após a germinação.

O quarto ensaio foi instalado no período das águas, no mês de dezembro de 2004, na mesma área do terceiro ensaio, com preparo do solo, adubação e condução semelhantes ao cultivo anterior. Foram realizadas duas pulverizações preventivas com calda bordalesa a $1 \%$, aos 30 e 50 dias após a emergência, para controle de doenças fúngicas, comuns nessa época, principalmente, manchaangular.

\section{RESULTADOS E DISCUSSÃO}

Os resultados da análise de variância conjunta (Tabela 1) mostram que houve interação altamente significativa entre cultivares e ambientes, indicando que as condições específicas nos dois ambientes estudados influíram diferentemente no rendimento de grãos e no estande final.

Os dados de produção média dos ensaios conduzidos encontram-se na Tabela 2. No período de inverno de 2003, em área de baixa fertilidade, usando sistema de irrigação, as cultivares Diamante Negro, Talismã, Xamego e Marfim sobressaíram-se, devendo-se destacar as cultivares de tipo carioca e preto que são as mais consumidas na região (YOKOYAMA \& STONE, 2000). No período das águas, situação que pode ser considerada desfavorável, devido ao excesso de chuvas e condições

TABELA 1 - Quadrados médios da análise de variância conjunta, média e coeficiente de variação do rendimento de grãos ( $\mathrm{kg} / \mathrm{ha})$, estande final (plantas por metro linear) de onze cultivares de feijoeiro em sistema orgânico de produção no Distrito Federal, nos anos de 2003 e 2004.

\begin{tabular}{lll}
\hline & Rendimento & Estande final \\
\hline Ambientes & $3178025.1 * *$ & $2061.9 * *$ \\
Cultivares & $101116.4 \mathrm{~ns}$ & $933.9 *$ \\
Cultivares X & $95299.6 * *$ & $413.0 * *$ \\
Ambientes & & \\
Resíduo & 8211.5 & 119.7 \\
\hline Média (kg/ha) & 1928 & 10,3 \\
$\mathrm{CV}(\%)$ & 11,8 & 13,0 \\
\hline
\end{tabular}

ns - não-significativo

*, **significativo ao nível de $5 \%$ e $1 \%$ de probabilidade pelo teste $\mathrm{F}$, respectivamente. 
climáticas propícias ao desenvolvimento de doenças, principalmente fúngicas, a cultivar Radiante destacou-se das demais. Esse tipo de feijão tem a vantagem de ter ciclo curto (70 dias) que, na época das águas, proporciona menor tempo para desenvolvimento de doenças e, na lavoura irrigada, significa economia pela diminuição do número de dias de irrigação, permitindo ainda a colocação antecipada do produto no mercado, conseguindo melhores preços. Deve-se salientar, ainda, a boa aceitação desse tipo de feijão entre os consumidores de produtos orgânicos devido a seu aspecto visual e seu peso de 100 grãos, com média de 44 gramas, características também presentes na cultivar Jalo Precoce, que teve produtividade que não diferiu estatisticamente neste ensaio. Ainda as cultivares Valente (preto) e Talismã (carioca) podem ser indicadas para esse tipo de situação, por terem boa procura pelos consumidores.

Em relação ao aspecto fitossanitário, a doença que atacou com maior severidade foi a mancha-angular, e a cultivar que apresentou maior susceptibilidade ao seu ataque foi a Pérola, bastante prejudicada no período das águas. Ao atingir o estágio V4, foi constatado ataque de vaquinha (Diabrotica speciosa), acima do NDE, que foi satisfatoriamente controlado utilizando-se repelente feito com o próprio inseto, cuja aplicação foi realizada com intervalos de cinco dias durante quatro semanas. Utilizouse pulverizador costal manual, capacidade para 20 litros, pressão de trabalho de $300 \mathrm{kPA}$ (45 PSI), vazão de ponta a 45 PSI: $600 \mathrm{ml} / \mathrm{min}$., com um volume de 400L/ha de calda, que foi feita usando-se tajujá (Cayaponia tayuya) como isca para capturar o inseto e em seguida batendo a medida de um copo de insetos e um litro de água no liquidificador, coando-se e completando-se o volume do tanque com água.

No ano de 2004, buscou-se avaliar o comportamento das mesmas cultivares estudadas no ano anterior, numa área com fertilidade equilibrada, onde já se praticava o cultivo orgânico há alguns anos, servindo, pois, para indicar materiais mais adequados à rotação de culturas, principalmente, para áreas utilizadas há algum tempo com hortaliças. Os dados de produção média encontram-se na Tabela 2.

No período da seca de 2004, usando sistema de irrigação, as cultivares Aporé, Marfim e Vereda sobressaíram-se. Já, na época das águas, as cultivares Marfim, Pérola, e Diamante Negro distingüiram-se das demais, podendo ser indicadas para esse tipo de situação, devendo-se destacar as cultivares Pérola e Diamante Negro, dos tipos carioca e preto, que têm maior procura na região (YOKOYAMA \& STONE, 2000).
Em relação ao aspecto fitossanitário, a doença que atacou com maior severidade neste ano agrícola foi a mancha-angular que, no período de inverno, foi mais acentuada na cultivar Talismã e, no período das águas, cujas condições de temperatura e umidade foram favoráveis ao seu desenvolvimento, atingiu com maior severidade a cultivar Radiante, prejudicando bastante seu estande final e, conseqüentemente, sua produtividade.

$\mathrm{O}$ ataque de pragas no período da seca não chegou a atingir o nível de dano econômico e no período das águas houve necessidade de duas aplicações de calda de Nim a $1 \%$ para controle de percevejo-verde (Nezara viridula).

A comparação entre rendimentos alcançados no sistema orgânico e no sistema convencional torna-se útil, pois no segundo o aporte de insumos e agrotóxicos é grande, ficando em torno de $33 \%$ do custo de produção de uma saca de feijão (SOARES et al., 2005), além de todos os malefícios causados para o produtor, para o consumidor e para o meio ambiente. Se no sistema orgânico as produtividades obtidas forem semelhantes às do convencional, pode-se inferir que é mais vantajoso produzir feijão nesse sistema, tanto por evitar os problemas citados, como pelo melhor preço conseguido pelo produtor, ao colocar seu produto no mercado. Considerando-se que a média de produtividade de feijão convencional no Distrito Federal é superior à média nacional (CONAB, 2006), devido ao alto índice de tecnologia praticado na região, pode-se confirmar um dos objetivos deste estudo mostrando que o rendimento conseguido pela agricultura orgânica, pode estar próximo do rendimento conseguido pela agricultura convencional comparando-se a média de todos os materiais estudados com a média alcançada no sistema convencional da região no ano de 2004. Como exemplo, pode-se citar a cultivar Marfim que teve produtividade estatisticamente superior às demais, tanto no período de inverno $(3408 \mathrm{~kg} /$ ha) quanto no período das águas $(2788 \mathrm{~kg} / \mathrm{ha})$, sendo superior à média de $2626 \mathrm{~kg} / \mathrm{ha}$ obtida por Del-Peloso et al. (2004) nos ensaios de VCU em sistema convencional na região. A cultivar Pérola, que ocupa $85 \%$ da área plantada com feijão no Distrito Federal (SOUSA, 2002), em ensaios conduzidos no inverno e no período das águas de 2004 na região por Braz et al. (2005), teve produtividade média de $2317 \mathrm{~kg} / \mathrm{ha}$, inferior à média conseguida no inverno e no período das águas em sistema orgânico que foi de $2748 \mathrm{~kg} /$ ha no mesmo ano.

O sistema de condução da lavoura com irrigação e sem irrigação e o tipo de área escolhida para sua instalação, área em conversão anteriormente com pastagens, com baixa fertilidade (2003) ou área já estabelecida com agricultura 


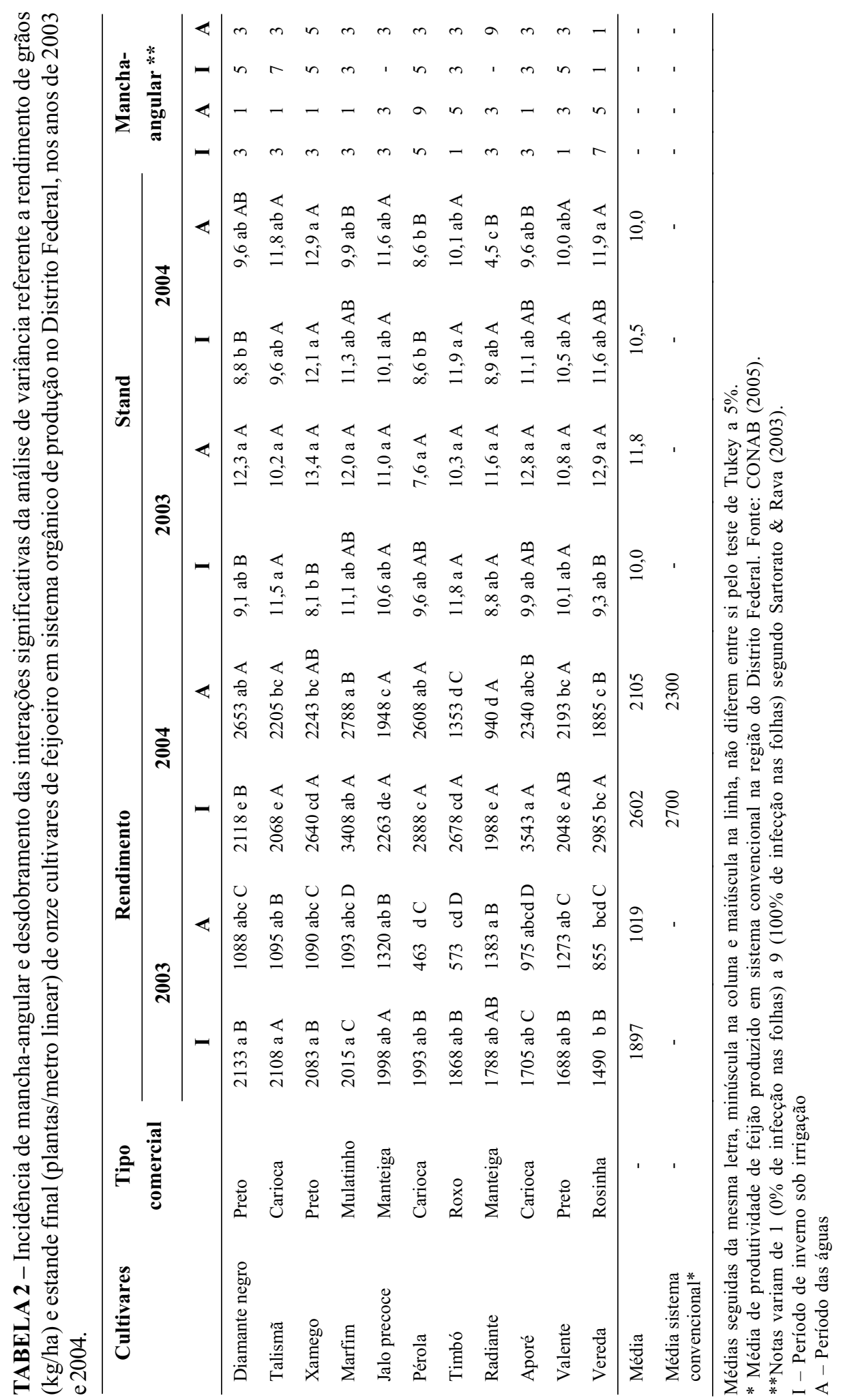


orgânica com fertilidade corrigida (2004), tiveram diferenças significativas de acordo com a análise conjunta (Tabela 2). A situação ideal entre as estudadas foi aquela onde se instalou o ensaio numa área com fertilidade corrigida, no inverno, usando sistema de irrigação. A pior situação seria o plantio em áreas de baixa fertilidade, refletindo a situação de produtores que iniciam o cultivo orgânico em áreas de pastagens degradadas ou em repouso há alguns anos, sem passar pelo prazo de conversão. Nesse tipo de solo e na época das águas, em que é maior a incidência de doenças, a produtividade é bastante prejudicada apesar dos benefícios oriundos do equilíbrio nutricional promovido pela adubação orgânica.

\section{CONCLUSÕES}

As cultivares Marfim, Xamego, Diamante Negro e Talismã apresentaram melhor desempenho em área com baixa fertilidade, no período de inverno sob irrigação.

As cultivares Radiante, Jalo Precoce, Valente e Talismã apresentaram melhor desempenho em área com baixa fertilidade e cultivada no período das águas.

Devido à maior resistência a doenças, comportamento estável, capacidade produtiva e aceitação pelo mercado consumidor, a cultivar Talismã apresenta maiores possibilidades de sucesso para cultivo orgânico em áreas anteriormente utilizadas com pastagens ou que estiveram em repouso por mais de anos.

As cultivares Aporé, Marfim e Vereda apresentaram melhor desempenho em área já estabelecida com agricultura orgânica, no período de inverno sob irrigação.

As cultivares Marfim, Pérola, Aporé e Diamante Negro apresentaram melhor desempenho em área já estabelecida com agricultura orgânica, no período das águas.

É possível produzir feijão em sistema orgânico, alcançando produtividades semelhantes às obtidas no sistema convencional.

\section{REFERÊNCIAS BIBLIOGRÁFICAS}

BRAZ, A. J. B. P.; FERREIRA, S. B.; SILVA, I. D. C. da; CARVALHO, W. P. de; SANTOS, C. A. G. dos; AGUIAR, P. A. de. Avaliação de linhagens de feijoeiro comum do grupo carioca, no Estado de Goiás e Distrito Federal, em 2003 e 2004. In: CONGRESSO NACIONAL DE PESQUISA DE FEIJÃO, 8., 2005, Goiânia, GO. Anais... Goiânia: UFGO, 2005. p. 328-330.
CARVALHO, Y. M. C. de. Agroecologia e regulação: contribuição metodológica para o fortalecimento de um processo social. In: AMBROSANO, E. Agricultura ecológica. Guaíba: Agropecuária, 1999. p. 265-301.

CONAB. Conab. Brasília, DF, 2006. Disponível em: http:www.conab.gov.br>. Acesso em: 17 nov. 2006.

DEL-PELOSO, M. J.; FARIA, L. C. de; COSTA, J. G. C. da; RAVA, C. A.; CARNEIRO, G. E. S. 'BRS Marfim': new common bean cultivar from "mulatinho" comercial grain type. Annual Report of the Bean Improvement Cooperative, [S.1.], v. 47, p. 321-322, 2004.

KHATOUNIAN, C. A. Estratégias de conversão para a agricultura orgânica. In: AMBROSANO, E. Agricultura ecológica. Guaíba: Agropecuária, 1999. p. 57-71.

QUINTELA, E. D. Manejo integrado de pragas do feijoeiro. Santo Antônio de Goiás: Embrapa-CNPAF, 2001. 27 p. (Circular técnica, 46).

RAVA, C. A.; MOLINA, J.; KAUFFMANN, M.; BRIONES, I. Determinación de razas fisiolóicas de Colletotrichum lindemuthianum em Nicaragua. Fitopatologia Brasileira, Brasília, v. 18, n. 3, p. 388-391, jul./set. 1993.

RAVA, C. A.; SARTORATO, A.; COSTA, J. G. C. Reação de genótipos de feijoeiro comum ao Fusarium oxysporum $\mathrm{f}$. sp. phaseoli em casa de vegetação. Fitopatologia Brasileira, Brasília, v. 21, n. 2, p. 296-300. abr.jun. 1996.

SARTORATO, A.; RAVA, C. A. Controle químico da mancha angular do feijoeiro comum. Summa Phytopathologica, Jaboticabal, v. 29, n. 2, p. 202-204, abr./jun. 2003.

SOARES, D. M.; THUNG, M.; AIDAR, H.; KLUTHCOUSKI, J. Estimativa de custo de produção de feijão: coeficientes técnicos, custos, rendimentos e rentabilidade. In: CONGRESSO NACIONAL DE PESQUISA DE FEIJÃO, 8., 2005, Goiânia. Anais... Goiânia: Embrapa, 2005. p. 881-883.

SORAGY, R.; SANTINATO, R.; CORREIA, J. P. Estudo da viabilidade técnica na produção de café orgânico e organomineral nas condições de cultivo nos cerrados. In: CONGRESSO BRASILEIRO DE PESQUISAS CAFEEIRAS, 24., 1998, Poços de Caldas. Anais... Rio de Janeiro: MAAPROCAFÉ, 1998. p. 91-93.

Ciênc. agrotec., Lavras, v. 31, n. 3, p. 605-611, maio/jun., 2007 
SOUSA, J. B. de. Conjuntura rural do Distrito Federal: 2002. Brasília, DF: Emater-DF, 2002. 87 p.

WANDERLEY, A. L. Grandes culturas e tomate processado. In: WORKSHOP DE OLERICULTURA ORGÂNICA NA REGIAO AGROECONOMICA DO DISTRITO FEDERAL,
1., 2001, Brasília. Anais... Brasília, DF: Embrapa Hortaliças, 2001. p. 113-118. (Documentos, 31).

YOKOYAMA, L. P.; STONE, L. F. Cultura do feijoeiro no Brasil: características da produção. Santo Antônio de Goiás: Embrapa Arroz e Feijão, 2000. 75 p. 